\title{
SRI LANKA POLICE SERVICE, A FORCE TO BE RECKONED WITH PRIDE; VIEW OF A FORENSIC PATHOLOGIST.
}

The Forensic Pathologists of Sri Lanka work very closely with the police for the administration of justice. The police act as one of the main pillars in the medico-legal system of Sri Lanka. The police service should be recognized as the hub of criminal investigations pertaining to both the living and the dead. This letter is written in the context of how the police can better utilize the services of a Forensic Pathologist who also attends to clinical cases as a Judicial Medical Officer.

In Sri Lanka the Forensic Pathologist who also works as a Judicial Medical Officer covering clinical cases of forensic significance may be the first contact in most cases following an issuance of a Medico Legal Examination form (MLEF). In all instances the police may not be present at the time of examination but in situations such as a victim of a sexual assault, child abuse and examination for intoxication a suspect to be kept in police custody especially in the nights where the police always accompany the individual. It is of paramount importance that the accompanying police officer understands what the Judicial Medical Officer is trying to communicate regarding the findings such as an attenuated hymen as a result of repeated vaginal penetration, stretchable hymen which can accommodate an adult penis without sustaining any injuries and cases of alcohol intoxication complicated with natural pathology. This is equally true for the police officers who present themselves for complicated autopsies with potential medico-legal issues. Though the Judicial Medical Officer is supposed to talk in simple layman language, there still can be instances where the exact lay term may not be available as mentioned above. The police officer, again in most cases acts as a link to the Attorney General's department. The understanding of information written and spoken is very vital for the administration of justice. Srilankan police officers with excellent literacy rate should be made familiar with the terms the Judicial Medical Officers use when examining and reporting on clinical forensic cases. This can be achieved by training police officers of excellence who will have commendable communication skills, reasonable knowledge in medical terminology and high calibre investigating skills. These police officers would be an asset to the medical forensic community where they can discuss matters of highest confidentiality while the personal integrity of a practicing forensic physician is preserved. In a complex homicide where the cause of death could not be ascertained on the first instance but needs detailed investigations and more information from other categories of forensic professionals to conclude the case then the role of the police officer would be really valued. These are not expectations which cannot be met. The Judicial Medical Officers would whole-heartedly support the Sri Lanka Police Force to emerge as a regional giant equipped with high calibre police personnel. One recommendation the writers would suggest to make is that more and more young and qualified police officers be encouraged by the Police Department to follow forensic-based short courses conducted by the local universities.

The same is applicable when it comes to the investigation of deaths. In high profile cases, the police may have to deal with several agencies including Attorney General's department, Government Analyst's department, Office of the JMO etc. Here again, the police officer's role is outstanding and unique in the sense that the confidential information need to be shared and any new information need to be properly 
communicated among the concerned parties. Therefore the police officer who may be wishfully called as 'police detective' is respected as an officer of excellence with high practicing skills and sound knowledge in investigation. The Forensic Pathologists practicing in Sri Lanka would never hesitate to share their knowledge in building up a highly professional Police Service for the benefit of the criminal justice system of the country.

The Scene of Crime Officers (SOCO) as a unit is praiseworthy. Their services are often unchallengeable and in par with those of any developed country. This is based on the experiences the writers had during their exposure to forensic services in developed countries. The writers would like to stress that their experiences are in anyway not inferior to Crime Scene Investigation (CSI) officers of any other country and infact they are more equipped to share their unique experiences with their colleagues in different parts of the world where mass-disasters, underworld killings, bomb explosions, rifled firearm deaths and exhumations of mass-graves are a real forensic rarity. This assertion is again made with relevant to the first hand experiences the writers had during their stay in developed countries. It is the writers desire to conduct research on SOCO performances and enlighten the Sri Lankan public in coming years. They have so far handled several challenging cases of note as witnessed by the authors. The Forensic Pathologists would like to see them emerge as a task force well equipped with all the facilities and a well sought-after companion in high profile cases.

The Forensic Pathologist's role in conducting investigations regarding victims of road traffic injuries is often minimal. Since Traffic Medicine as a different entity is not yet well practiced among forensic practitioners of the present-day, many an information where a forensic pathologist can provide is not sought after. When there is a firm requirement from the investigating police officers, the forensic pathologists would also gear themselves up to provide that information.

At the end of the day from the authors' point of view, a police officer who is well trained and knowledgeable, well equipped with the current trends and who can work with a Forensic specialist with utmost confidentiality, trust and personal integrity is a real asset. Thus in future Sri Lanka, we all can be proud as a nation with a high calibre and outstanding police force acting as the main pillar in the criminal justice system.

1) Dr. P. Paranitharan MBBS, DLM, MD (For.Med)

Faculty of Medicine, University of Kelaniya, Sri Lanka.

2) Dr Sanjaya Hulathduwa MBBS, DLM, MD, DMJ (clin et. path) Faculty of Medical Sciences University of Sri Jayawardenapura, Sri Lanka. 